\title{
Dimensões Políticas e Pedagógicas da Formação Educacional Continuada
}

\section{Political and Pedagogical Dimensions of Continuing Educational Formation}

\author{
Debora Gomes ; João Luiz Gasparin ; Rita de Cássia da Silva Oliveira ${ }^{\mathrm{a}}$ \\ aUniversidade Estadual do Centro-Oeste. PR, Brasil. \\ bUniversidade Estadual de Ponta Grossa, Programa de Pós-Graduação Stricto Sensu em Educação. PR. Brasil. \\ 'Universidade Estadual de Maringá, Programa de Pós-Graduação Stricto Sensu em Educação. PR. Brasil. \\ *E-mail: deboragomes@unicentro.br
}

\begin{abstract}
Resumo
A formação continuada dos professores tem sido alvo de debates e discursos políticos frequentes nos últimos anos. Nessa direção, este estudo buscou analisar o fato da formação educacional continuada ter-se tornado tão necessária e debatida nas dimensões políticas e pedagógicas da educação. De cunho qualitativo e pautada no método do materialismo histórico-dialético, esta pesquisa buscou apontar, por meio de uma análise crítica de documentos internacionais e nacionais, leis, livros, artigos científicos, teses e dissertações, as abordagens que cercam a formação continuada, trazendo à tona questões pertinentes que ajudam a entender seu significado/sentido, sua historicidade, suas implicações, suas relações, a fim de provocar "novos" entendimentos e "novas" práticas acerca desse tema de relevância para a ação docente. Para uma efetiva formação continuada são necessários novos programas, novos métodos, uso de novos recursos tecnológicos para articular os saberes científico-culturais indispensáveis para a aprendizagem dos alunos como cidadãos e futuros profissionais. Isso deve ser previsto tanto na dimensão teórica quanto na prática em todos os cursos e processos de formação continuada. Desta forma, emergem duas conclusões essenciais. A primeira diz respeito à necessidade de que os professores conheçam as políticas públicas de educação e a respectiva proposta de formação continuada que delas decorre. A segunda aponta para o indispensável dever profissional de aprofundar e atualizar o conteúdo específico que ministram, tanto em sua dimensão teórica quanto na dimensão de uso social.
\end{abstract}

Palavras-chave: Formação Docente. Políticas Públicas. Dimensão Teórica e Prática.

\begin{abstract}
The continuing education of teachers has been the subject of frequent political debates and speeches in recent years. In this direction, this study sought to analyze the fact that continuing educational training has become so necessary and debated in the political and pedagogical dimensions of education. Of a qualitative nature and based on the method of historical-dialectical materialism, this research sought to point out, through a critical analysis of international and national documents, laws, books, scientific articles, theses and dissertations, the approaches that surround continuing education, bringing surfacing pertinent questions that help to understand its meaning/sense, its historicity, its implications, its relationships, in order to provoke "new" understandings and "new" practices about this theme of relevance for the teaching action. For effective continuing education, new programs, new methods, use of new technological resources are necessary to articulate the scientific-cultural knowledge indispensable for the learning of students as citizens and future professionals. This must be foreseen both in the theoretical dimension and in practice in all courses and processes of continuing education. In this way, two essential conclusions emerge. The first concerns the need for teachers to be aware of public education policies and the respective proposal for continuing education that results from them. The second points to the indispensable professional duty to deepen and update the specific content they teach, both in its theoretical dimension and in the dimension of social use.
\end{abstract}

Keywords: Teacher Education. Public policy. Theoretical and Practical Dimension.

\section{Introdução}

A formação continuada de professores tem sido alvo de debates e discursos políticos nos últimos anos e, embora seja mencionada já desde a década de 30 do século passado, está mais presente hoje nas ações dos professores e pesquisadores, bem como nos documentos publicados pelos responsáveis pelas políticas públicas educacionais do Brasil.

Diferentes ações têm sido propostas por órgãos educacionais, objetivando inserir inovações para melhoria das práticas pedagógicas, além de recursos financeiros investidos pelo Ministério da Educação - MEC, na implantação de Programas destinados à formação continuada. Mas, observase, em relatos dos professores da educação básica, com os quais temos a oportunidade de conviver no dia-a-dia das escolas, que a formação inicial não os tem preparado para as reais necessidades. Não podemos apontá-la como única responsável pela situação atual da educação e, por conseguinte, sabemos que a formação continuada por si só não dará conta de resolver os problemas que assolam a educação, no entanto, diversos autores têm afirmado que a formação continuada poderá contribuir como uma das várias ações que estão sendo elencadas em torno da melhoria da qualidade do ensino brasileiro.

Acreditamos que na formação inicial não se esgota a formação necessária para a atuação do professor. Nesse sentido, a formação continuada se configura como uma possibilidade de compreender melhor a prática e atuar frente aos desafios 
que se impõem pela realidade escolar, no momento em que a compreensão de determinadas ações didático-pedagógicas se estruturam no cotidiano da ação docente e discente, e exigem solução.

A palavra formação vem do latim formatione e é definida como "ato, efeito ou modo de formar; constituição, caráter, maneira por que se constitui uma mentalidade, um caráter, ou um conhecimento profissional", ou seja, podemos afirmar que a formação se caracteriza pela aquisição de conhecimentos que irão constituir nossa maneira de agir, que darão um norte para nossas ações, seja reproduzindo, seja negando, seja produzindo novos conhecimentos e novas ações (FORMAÇÃO, 2004).

Já a palavra continuada é definida como "o que dura sem interrupção, repetido, seguido, contínuo", portanto, subentende-se que formação continuada é um processo de aquisição de conhecimento ininterrupto. Vale ressaltar que este termo, tão difundido atualmente, tem sido muito utilizado ao longo de décadas, muitas vezes com nomenclaturas diferentes: educação permanente, estudo permanente, formação em serviço. Independentemente do conceito utilizado, observase a necessidade do ser humano e a possibilidade de estar, ao longo de toda sua vida, em processo de formação (CONTINUADA, 2014).

Melo (1999, p. 47), define formação “[...] como um processo inicial e continuado que deve dar respostas aos desafios do cotidiano escolar, da contemporaneidade e do avanço tecnológico".

Adotamos, neste estudo, o termo formação continuada, referindo-nos a todo e qualquer estudo, (pós-graduação, cursos, participação em eventos, oficinas, palestras, estudo de textos, artigos, livros, etc.), realizado pelos profissionais da educação, concomitantemente à sua atuação.

Vale destacar que a continuidade da formação visa, também, melhorar a formação inicial, não com o objetivo de um conserto destinado a dar conta das falhas da formação universitária, mas como uma oportunidade para produzir inovações pedagógicas e enfrentar desafios das mudanças constantes que ocorrem na sociedade, ou seja, contribuir para que ocorra transmissão de saberes objetivos, socialmente construídos e que "[...] passaram a ter validade universal para o gênero humano e que devam ser transmitidos pela escola" (DUARTE, 2000, p. 108).

Não podemos deixar de considerar que os cursos, oficinas, palestras, dentre outras atividades oferecidas no processo de formação continuada, não conduzem necessariamente às ações didático-pedagógicas ou às mudanças no direcionamento das atividades do professor; no entanto, não existem mais dúvidas de que tais ações são fundamentais para motivar, reafirmar ou atualizar a prática docente.

Partimos do pressuposto de que a formação continuada do professor deve tomar como base sua prática pedagógica, e desta forma, situar como finalidade dessa prática levar os alunos a dominarem os conhecimentos acumulados historicamente pela humanidade, ou seja, entende-se que o papel político da formação continuada de professores e o consequente "[...] papel política da educação se cumpre [...] quando se garante aos trabalhadores o acesso ao saber, ao saber sistematizado" (SAVIANI, 2011, p. 63).

Nessa perspectiva, é importante ressaltar o dilema entre os saberes dos professores e a legitimação desses entre os pesquisadores, ou seja, uma das discussões, que vêm ocorrendo durante as formações continuadas, é saber se os responsáveis por elas têm-se incumbido da "[...] tarefa de construir um repertório de saberes baseado no estudo dos saberes profissionais dos professores", o que torna necessário "um exame crítico das premissas que fundamentam as crenças de uns e de outros em relação à natureza dos conhecimentos profissionais" (TARDIF, 2014, p. 28).

Toda e qualquer formação deve sempre partir da escola e para ela retornar, sendo inerente ao seu cotidiano, bem como aos interesses de professores e alunos preocupados com um fazer constante voltado para construção/reconstrução do conhecimento. É necessário irmos além da mera transmissão de conhecimentos, superar a visão da "educação bancária" (FREIRE, 1987), que vê o aluno e/ou o professor como um objeto que recebe depósitos diários de conhecimentos.

Neste sentido, este estudo buscou analisar porque a formação continuada se tornou tão necessária, debatida e, de certa forma, considerada tão importante para a área da educação.

\section{Desenvolvimento}

\subsection{Metodologia}

No que tange aos procedimentos, a fim de atingir os objetivos propostos, recorremos às discussões que têm sido feitas nas publicações a respeito de tal temática, constituídas principalmente de documentos, livros, artigos científicos, teses, dissertações e leis.

Os referidos materiais foram selecionados a partir da relação com o objeto de estudo, bem como, da relevância em relação aos desdobramentos que se seguiram nos sistemas de ensino brasileiro, no que se refere à implantação e implementação da formação continuada, desta forma, utilizou-se a consulta nos sítios do Scielo e Biblioteca Digital Brasileira de Teses e Dissertações.

Trata-se de uma pesquisa teórico-descritiva, do tipo qualitativa $^{1}$, na perspectiva do materialismo históricodialético, que procura compreender a formação educacional continuada em seu processo e complexidade social e cultural, trazendo à tona questões pertinentes que ajudam a entender seu significado/sentido, sua historicidade, suas implicações,

\footnotetext{
1 No sentido de olhar para as camadas intrincadas, detalhadas, nuançadas, a partir da qualidade, e não da quantidade de dados analisados. Considerar a reincidência e complementaridade das informações, bem como, chegar em um ponto que seja possível identificar as múltiplas dimensões de determinado fenômeno.
} 
suas relações, a fim de provocar "novos" entendimentos e "novas" práticas acerca este processo de formação.

\subsection{Formação Continuada: aspectos das Políticas Públicas}

Para abordarmos qualquer tema relacionado à educação pública contemporânea, faz-se necessário discutir as políticas públicas que abarcam tal questão, políticas estas que são gestadas pelos governos federal, estadual ou municipal, mas que sofrem influência direta das organizações internacionais, dada a vinculação financeira do país com estas instituições.

No final do século XX e início do século XXI, a educação passou a ter destaque nas discussões em todos os âmbitos da sociedade, no entanto,

[...] no contexto de mudanças macroeconômicas globais, orientadas por Estados hegemônicos e organismos multilaterais a seu serviço, que contam com a anuência voluntária ou não dos demais países (subalternos e periféricos?), a educação, ao mesmo tempo em que é alvo da crítica de todos os matizes ideológicos por não responder às demandas sociais, passa por transformações de sua identidade histórica: de direito de cidadania - herdado do ideário liberal, da Revolução Francesa e do Estado de Bem-Estar, ou socialista - parece transformarse cada dia em um bem privado ou mercantil, isto é, moeda de troca entre indivíduos, entre indivíduos e organizações comerciais nacionais ou transnacionais, e mesmo entre nações nas suas transações mercantes (CAMARGO et al., 2003, p.727).

No documento Prioridades $Y$ Estrategias para la Educacion: examen del Banco Mundial ${ }^{2}$, publicado em janeiro de 1996, aparecem, como objetivos do Banco Mundial, o aumento do acesso à educação e a melhoria da qualidade. Para isto, diante do fato de que os gastos públicos neste setor são insuficientes e mal distribuídos, propõe-se a reforma do financiamento e da administração da educação, através de seis medidas (reformas) fundamentais:

Estas reformas são para dar mais prioridade para a educação; prestar atenção ao desempenho; concentrar eficientemente o investimento público em educação básica e recorrer em maior medida ao financiamento familiar para a educação superior; prestar atenção à equidade; aumentar a participação das famílias no sistema de ensino; dar autonomia às instituições para permitir uma combinação flexível de insumos educacionais (BANCO MUNDIAL, 2006, p. 99, tradução nossa). ${ }^{3}$

Se fizermos uma análise atenta, veremos que as seis propostas visam:

- considerar a educação responsável pelo sucesso ou não das pessoas no mercado de trabalho; caso o indivíduo não alcance grandes 'cargos', a culpa é dele mesmo, pois a educação foi oferecida;

- oferecer educação básica, pois é mais do que suficiente para preencher as vagas dos subempregos existentes;

- possibilitar equidade, o que não garante igualdade para todos e sim alguns direitos para aqueles que se encontram em condições críticas;

- dar autonomia para as instituições, que acabam buscando recursos em outros setores desobrigando o Estado de cumprir com seu papel.

- trazer a família, tornando-a responsável por meio de ações voluntárias por gerir a educação de seus filhos.

Segundo o documento do Banco Mundial (1996), a educação deve produzir conhecimentos, capacidades, valores e atitudes, pois isto é essencial para a ordem cívica, para a cidadania, para um crescimento econômico sustentável e para a redução da pobreza; por outro lado, suas medidas só servirão para afirmar uma sociedade excludente, onde cada um tem seu lugar próprio, pobre com trabalho de pobre, rico com trabalho de rico.

Este documento enfatiza que o conhecimento dos professores “[...] tem relação estreita e sistemática com o rendimento dos alunos" ${ }^{4}$, portanto os professores com amplo repertório de conhecimento e práticas de ensino são mais eficazes do que aqueles com um repertório limitado. Nessa perspectiva, o documento aborda que o ideal seria contratar professores "[...] com formação suficiente e conhecimentos demonstrados durante a avaliação de desempenho"5. Porém, como a forma de contratação de professores para a educação básica na rede pública é ineficaz na análise dos conhecimentos, este documento propõe a formação continuada como mecanismo para que os docentes possam avançar nos conhecimentos específicos e nas práticas pedagógicas (BANCO MUNDIAL, 1996, p.90, tradução nossa).

Para o Banco Mundial (1996, p.91), a formação continuada é uma estratégia para melhorar o conhecimento específico, as práticas pedagógicas dos professores e, consequentemente, a qualidade do ensino, por isso deve ser realizada por meio "[...] da apresentação de novas teorias e técnicas, as demonstrações de sua aplicação, a prática, a troca de informações e a formação continuada" (tradução nossa) ${ }^{6}$, além de estar diretamente vinculada à prática da sala de aula.

Vale ressaltar que as propostas do Banco Mundial não são contemporâneas, pois segundo Coraggio (1996, p.97),

$[\ldots]$ embora as propostas educativas oficiais do Banco

2 A discussão a partir desse documento neste artigo, decorre do fato de que a adequação das políticas educacionais do Brasil às orientações de organismos multilaterais, teve início na década de 1980, se intensificou nos anos 1990, desde a realização da Conferência Mundial sobre Educação para Todos, na Tailândia, cujo objetivo foi formular políticas para escola de países emergentes compatíveis com o funcionamento do capitalismo globalizado (LIBÂNEO, 2013).

3 Esas reformas consisten en dar más prioridad a la educación; prestar atención al rendimiento; concentrar eficientemente la inversión pública en la educación básica y recurrir en mayor medida al financiamiento familiar de la enseñanza superior; prestar atención a la equidad; intensificar la participación de los hogares en el sistema de educación, dar autonomía a las instituciones a fin de permitir una combinación flexible de los insumos educacionales.

$4[\ldots]$ tiene una relación estrecha y sistemática con el rendimiento de los alumnos

$5[\ldots]$ con formación suficiente y conocimientos demostrados durante la evaluación del desempeño

6 [...] la presentación de nuevas teorías o técnicas, las demostraciones de su aplicación, la práctica, el intercambio de información, y el entrenamiento continuado. 
Mundial sejam muitas vezes interpretadas como uma resposta contemporânea à inédita problemática atual, é importante lembrar que essa linha de pensamento esteve presente no Banco desde os anos 70, quando aparecia em parte como uma correta chamada de atenção, dirigida àqueles que se concentravam na análise das determinantes socioeconômicas externas, para que considerassem e agissem sobre o que acontecia na sala de aula. Mais ainda, já naquela época estavam elaboradas praticamente todas as receitas que hoje podem ser vistas como resposta específica à crise do sistema educacional, o que nos coloca diante de um caso, seja de extraordinária premonição, seja do predomínio de uma rígida teoria sobre uma realidade mutável e diferenciada.

Segundo Fonseca (2003, p.231-232), duas tendências são perceptíveis no documento do Banco:

a primeira busca integrar os objetivos dos projetos educacionais à política de desenvolvimento do Banco para a comunidade internacional; nesta modalidade, situam-se os projetos de educação fundamental integrados a projetos setoriais específicos, como os de desenvolvimento rural, por exemplo. A segunda atribui à educação caráter compensatório, entendido como meio de alívio à situação de pobreza no Terceiro Mundo, especialmente em períodos de ajustamento econômico.

Percebe-se, já aí, a atribuição da tarefa de diminuir a pobreza no mundo, pela educação.

Além dos documentos do Banco Mundial, também foram escritos documentos pela Comissão Econômica para a América Latina e Caribe - CEPAL; pela Organização das Nações Unidas para a Educação, Ciência e a Cultura UNESCO e pela Conferência Mundial sobre Educação para Todos.

Quanto à CEPAL, segundo Oliveira (2003), mesmo não sendo uma instituição voltada especialmente para a política educacional, nesta última década, destacou-se como principal fonte de direcionamentos para esta área em todo o continente latino-americano e região caribenha.

Criada pela Organização das Nações Unidas (ONU), em 1948, com o objetivo de coordenar as políticas de desenvolvimento dos países da América Latina, incorporou posteriormente os países do Caribe, com também o objetivo de desenvolvimento social.

Tendo em sua composição 41 países membros e 7 associados, a CEPAL objetiva, dentre outros:

- Promover o desenvolvimento econômico e social mediante a cooperação e integração regionais e sub-regionais;

- Reunir, organizar, interpretar e difundir informação e dados relativos ao desenvolvimento econômico e social da região;

- Prestar serviços de assessoramento aos governos, planificar, organizar e executar programas de cooperação técnica;

- Formular e promover atividades e projetos de assistência para o desenvolvimento que se adéquem às necessidades e prioridades da região (OLIVEIRA, 2003, p.2).

Segundo Oliveira (2003), o documento Educación y conocimiento; eje de la transformación productiva com equidad, produzido em 1992, representa a primeira ação da CEPAL no sentido de uma política de articulação entre educação, conhecimento e desenvolvimento, ou seja, que considera a educação como eixo norteador para edificação de uma nova realidade econômica e social nos países em desenvolvimento.

Neste documento, dentre as sete vertentes das propostas de políticas, vale ressaltar a quinta e sexta que abordam respectivamente "[...] profissionalização e protagonismo dos educadores, compromisso financeiro da sociedade com a educação, a capacitação e o desenvolvimento científicotecnológico" (CEPAL, 1995, p.11).

Já quanto à sétima vertente, não fica claro se o compromisso é do Estado ou da sociedade, que pode ser a civil, ou seja, firma um compromisso com a educação e capacitação, sem especificar quem é que vai se responsabilizar por isso.

Quando o documento aborda a Cooperação Regional e Internacional, já no primeiro campo afirma que a formação de recursos humanos deve visar "[...] à utilização mais eficiente da capacidade instalada nas universidades e centro acadêmicos", deixando ao final bem claro que as linhas de cooperação visam:

1) melhoria da qualidade educacional; 2) introdução de inovações educacionais (níveis fundamental e médio); 3) elevação do grau de credibilidade de instituições, programas e unidades da educação superior; 4) formação de professores e pesquisadores de nível universitários; 5) reforma institucional e administrativa; 6) capacitação técnica; 7) pesquisa educacional; 8) intercâmbio de alunos; e 9) cooperação estratégica (CEPAL, 1995, p. 12-13).

Observa-se que o texto utiliza o termo capacitação técnica, ou seja, formar mão-de-obra operante, ou ainda, preparar rapidamente para ações pontuais, paliativas e que podem contribuir para mascarar a realidade. $\mathrm{O}$ único momento em que o documento faz alguma menção que possa reportar à formação continuada é quando aborda os requisitos da nova educação, baseados na "sociedade do conhecimento" (tradução nossa) ${ }^{7}$, destacando que a educação continuada é uma atividade inerente a esta sociedade; ou seja, na sociedade do conhecimento, o processo educativo não possui um término, mas é permanente, considerando que dever-se-á levar a sério o princípio de que se aprende para a vida e não para a escola, mas no sentido de atender as demandas do trabalho disponível à população.

Para a CEPAL, devemos reorganizar o sistema educacional, implantando mecanismos que dêem maior atenção à qualidade da educação, pois os êxitos e atrasos no campo econômico, político e social, podem ser explicados pela qualidade do serviço educacional oferecido (OLIVEIRA, 2003, p.3). Ou seja, devemos articular produção de conhecimento com produção de bens para termos êxitos econômicos e é nessa perspectiva que deve

7 iii) En la "sociedad del conocimiento", el concepto de educación terminada carece de sentido. La educación continua, especialmente de las personas con alto nivel académico, será una actividad floreciente del futuro, pese a que las escuelas y universidades la miran todavía con desconfianza, si pueden, ni siquiera la consideran (CEPAL, 1995, p.105). 
ocorrer a formação dos professores.

Enquanto política educacional adequada aborda que, embora a eficiência do sistema educacional esteja em grande parte atrelada aos investimentos, a estratégia educacional adotada em relação às políticas educacionais e de capacitação é tão importante quanto, devendo assumir dentre várias características, a política de valorização do magistério que "[...] se materializa em respeito social e salários adequados, além das formas diversas de estímulo e garantia de condições adequadas de aprimoramento profissional e pessoal" (CEPAL, 1995, p.172).

A Declaração Mundial sobre Educação para Todos e Plano de Ação para Satisfazer as Necessidades Básicas da Aprendizagem (1990, p.2-3), destaca que:

[...] a educação é um direito fundamental de todos, mulheres e homens, de todas as idades, no mundo inteiro;

[...] a educação pode contribuir para conquistar um mundo mais seguro, mais sadio, mais próspero e ambientalmente mais puro, e que, ao mesmo tempo, favoreça o progresso social, econômico e cultural, a tolerância e a cooperação internacional;

[...] a educação, embora não seja condição suficiente, é de importância fundamental para o progresso pessoal e social;

[...] o conhecimento tradicional e o patrimônio cultural têm utilidade e valor próprios, assim como a capacidade de definir e promover o desenvolvimento;

[...] a educação que hoje é ministrada apresenta graves deficiências, que se faz necessário torná-la mais relevante e melhorar sua qualidade, e que ela deve estar universalmente disponível;

[...] a educação básica adequada é fundamental para fortalecer os níveis superiores de educação e de ensino, a formação científica e tecnológica e, por conseguinte, para alcançar um desenvolvimento autônomo;

[...] a necessidade de proporcionar às gerações presentes e futuras uma visão abrangente de educação básica e renovado compromisso a favor dela, para enfrentar a amplitude e complexidade do desafio.

Com essas proposições, percebe-se que a educação enquanto direito de todos, deve contribuir para um mundo melhor, onde as pessoas progridam pessoal e socialmente. Desta maneira, caminharemos para mais qualidade na educação básica e, consequentemente, isso refletirá na educação superior, que, por meio da formação científica e tecnológica, contribuirá para um mundo melhor: "[...] mais seguro, mais sadio, mais próspero e ambientalmente mais puro, e que, ao mesmo tempo, favoreça o progresso social, econômico e cultural, a tolerância e a cooperação internacional", ou seja, propõe a educação como parte de uma rede responsável pelo progresso econômico que atenderá principalmente os interesses de uma minoria (CONFERÊNCIA MUNDIAL DE EDUCAÇÃO PARA TODOS, 1990, p.2).

Diante dessas conjunturas, observa-se que a educação vai passando por diversas mudanças, principalmente na sua estrutura. Tudo isto gera a reforma que vem acontecendo tanto no Estado quanto na Educação, a qual está pautada nas ações propostas pela ideologia neoliberal.

A UNESCO, que “[..] desempenha uma ação em várias frentes, das quais a mais importante é fazer do direito à educação uma realidade para todos os povos promovendo a ideia de paz e o espírito de justiça" (BORGES, 2001, p.308), consciente de que é necessário o combate ao analfabetismo e de que uma educação básica de qualidade deve ser garantida a todo cidadão, vem, a partir da década de 1990, avançando na busca de resolver a crise educacional atual, buscando por meio de diálogos com governantes, que os mesmos promovam ou ao menos planejem mudanças significativas em relação a uma educação plena aos cidadãos (ZANETTE, 2018).

Percebe-se que a concepção de educação sempre se apresenta pautada no futuro, entretanto, atualmente, são as relações presentes que têm determinado o papel da educação, onde a mesma tem-se configurado como agente responsável pelo sucesso ou não no mercado de trabalho, ou seja, a sociedade tem valorizado o alto nível escolar das pessoas, presumindo que estas estão qualificadas. A educação perpassa por várias ideias e teorias, contudo, porém por mais que sejam críticos à educação ou por mais que seja ela mal interpretada de uma forma ou de outra, todos recorrem a ela com vistas a garantia de um futuro melhor (PEREIRA, 2004).

Diante disto,

A educação do país não pode ficar na dependência de recursos provenientes da assinatura de acordos e projetos externos. Esses são temporários, estão mergulhados nos trâmites da burocracia, sujeitos aos jogos de interesses econômicos, políticos e dos acionistas das empresas de educação. Uma política nacional de educação demanda ações consistentes, coesas e contínuas e a integração com as demais políticas sociais. Exige dos governos firmeza e prudência ao definir a dotação orçamentária e zelo durante sua implementação, fiscalização e reavaliação. Exige que a sociedade civil participe e decida, e que tenha acesso aos mecanismos de controle sobre as ações do próprio Estado (SILVA, 2005, p.262).

Tal afirmação fica evidente, uma vez que a partir da década de mil novecentos e setenta, as políticas neoliberais apareceram como único meio de resolver os problemas dos países em desenvolvimento, só que, ao invés disso, o que se viu foram os governantes se submetendo às exigências políticas e econômicas que os tornaram vulneráveis e sujeitos às decisões das organizações multilaterais. As ações definidas por estas organizações acabaram

[...] não servindo aos interesses dos que delas precisavam, mas aos homens de negócio que as controlam e dos investidores e acionistas das empresas transnacionais que continuam mantendo seu lócus de produção de conhecimento ancorado nos países capitalistas centrais (SILVA, 2005, p.255).

No Brasil, a partir dos anos de 1990, o Governo Federal, boa parte dos Governos Estaduais e Municipais, juntamente com as elites empresariais, passaram a se sujeitar gradualmente às medidas neoliberais, ou seja, adotaram a ação de desmonte do Estado, utilizando o argumento de que este estava brecando o desenvolvimento do capital. Essa ação está gerando a privatização das políticas sociais - saúde, 
educação, previdência social e segurança -, redefinição das funções do Estado $^{8}$, abertura dos mercados, dentre outras (SILVA, 2005).

Os quatros pilares da Educação, divulgados por meio do Relatório da Comissão Internacional sobre Educação para o século XXI, publicado pela UNESCO em parceria com o MEC, constituíram-se como uma forte influência nessa perspectiva neoliberal, a qual invadiu as escolas e passou a fazer parte dos discursos de vários profissionais da Educação, sob a prerrogativa de que suas propostas de aprendizagem: "[...] aprender a conhecer, aprender a fazer, aprender a viver e aprender a ser" (DELORS et al., 1998, p.31), constituem-se na ajuda necessária para edificar um novo cenário educacional capaz de inserir a escola no contexto do mundo.

Um documento onde a realidade é descrita por meio da análise positivista, ou seja, que descreve a criança somente por ela mesma, além de não ser pautado pela práxis, desconsidera as relações sociais, econômicas, políticas e culturais, nas quais esta criança encontra-se inserida. Sem essa visão dialética, qualquer "receita" de aprendizagem como a proposta dos pilares, faz com que "[...] a educação deixe de ser parte do campo social e político para ingressar no mercado e funcionar a sua semelhança" (MARRACH, 2009, p.233).

Observa-se que as relações políticas e sociais da atualidade se encontram em desiquilíbrio, e consequentemente, as relações que se dão no interior das escolas, também recebem o reflexo deste desequilíbrio. Quem vem subsidiando as propostas da educação está pautado na discussão neoclássica que é a base da economia do capital humano, no entanto, devemos, por meio do domínio sobre o contexto histórico, social, econômico e político, desenvolver ações na educação que, ao menos minimizem a situação atual do país como um todo; mesmo "[...] reconhecendo a formação escolar como um requisito para a inserção no mercado de trabalho, não podemos aceitar a escola subordinada aos imperativos da economia" (OLIVEIRA, 2003, p.12).

Enfim, a sociedade não é solidária como se divulga a todo momento na mídia. Ela tem assumido o papel do Estado, ou seja, tem-se responsabilizado por ações que deveriam ser realizadas por meio de políticas públicas, o que não vem acontecendo, uma vez que o Estado não é mais providência, ou seja, o Estado tem-se eximido de suas obrigações e a Sociedade, por meio do "consentimento", passa a entender que "não custa nada colaborar". Nessa perspectiva, a educação deixa de ser redentora e passa a ser um mecanismo ideológico da sociedade neoliberal. Desta forma, as políticas para a educação acabam ficando à mercê do pensamento neoliberal, que, em sua plenitude, é orientado pelas ações e parâmetros do Banco Mundial:

Sistematizando, podemos afirmar que as medidas e as políticas governamentais no campo da formação de professores têm sido orientadas pelos parâmetros das políticas do Banco Mundial para a educação básica, dentre os quais se destacam: - $\quad$ aprofundamento do processo de 'ajuste' estrutural;

- enxugamento dos recursos do estado para a educação e consequente privatização;

- distribuição, centralização e focalização dos recursos para experiências que se adéquem aos princípios da reforma educativa em curso (isso inclui a criação dos ISEs e a transformação das atuais Escolas Normais em Cursos Normais Superiores e/ou ISEs);

- a massificação e o caráter de capacitação pedagógica (o retorno ao tecnicismo e ao pragmatismo) na formação de professores, em instituições específicas, exclusivas, sem história e orientadas pelos parâmetros da reforma educativa em curso que necessita "aterrissar na sala de aula", com o consequente rebaixamento das exigências de qualificação do corpo docente das instituições formadoras;

- diretrizes curriculares para a formação fundadas nas diretrizes curriculares para a educação básica e educação infantil e não em diretrizes curriculares que explicitem o currículo dos cursos de formação como espaços de análise da educação como disciplina, seus campos e métodos de estudo e seu status epistemológico; é preconizada uma 'sintonia fina' entre as instituições formadoras e a reforma educativa (ANFOPE, 2000, p.18-19).

Um exemplo que confirma a citação acima é a própria LDB de 1996, que, com a proposta de que os professores da Educação Básica passassem pela formação superior e com isto estivessem mais bem qualificados para atuarem junto às crianças deste nível de ensino, estabeleceu-se um prazo de dez anos para que os mesmos tivessem acesso ao Ensino Superior. Com isso, abriu-se um mercado promissor, onde as instituições privadas e os próprios Institutos Superiores de Ensino passaram a oferecer cursos a distância e de várias outras formas, mais parecidos com intensivos de estudos, do que uma licenciatura. Agora cabe refletirmos: até que ponto o diploma de licenciatura melhorará a qualidade de ensino? Isso não será mais uma medida paliativa? Os professores estarão com seus diplomas, mas a efetiva mudança na qualidade de ensino, se continuar atrelada somente à formação dos professores, principalmente formações com caráter de capacitação técnica e medidas paliativas, permanecerá estanque.

Nessa perspectiva, encontramos atualmente a ampla divulgação de trabalhos voluntários relacionados à formação continuada dos profissionais da educação. Vale destacar, que existe hoje no Brasil de acordo com o PNE (2014), a obrigatoriedade de garantir a todos os profissionais da educação básica formação continuada em sua área de atuação, considerando as necessidades, demandas e contextualizações dos sistemas de ensino (Meta 16); porém a efetivação disto, continua afirmando a mesma Meta, deve ser feita por meio de esforços articulados dos entes federativos para dimensionar a demanda por formação continuada e promover a respectiva oferta por parte das instituições públicas, consolidando assim um planejamento estratégico, em regime de colaboração; também existe uma verba do Fundo de Manutenção e

8 Um exemplo mais atual disso foi a aprovação pelo Plenário do Senado Federal, no dia 13 de dezembro de 2016, da Proposta de Emenda à Constituição n. 555, a qual prevê um teto para os gastos públicos e com isso irá congelar por vinte anos os investimentos, dentre outras áreas prioritárias, na educação. 
Desenvolvimento da Educação Básica e de Valorização dos Profissionais da Educação - FUNDEB, que pode ser destinada a esse fim. No entanto, o valor permitido para pagamento de horas-aula a profissionais que possam contribuir neste processo de formação, nem sempre é suficiente, obrigando as instituições a procurarem por outras alternativas: envio de um único representante para cursos a fim de que posteriormente o mesmo repasse o que aprendeu aos demais; parcerias com instituições superiores particulares que necessitam das escolas públicas para estágio e em contrapartida oferecem oficinas, palestras e cursos, geralmente ministrados por acadêmicos; convite à professores locais que submetem-se a trabalhos voluntários, dentre outros.

Enfim, a formação continuada acaba ficando à mercê do ditado popular "o que conseguir é lucro" ou ainda "de graça até injeção na testa", uma vez que muitas das Secretarias da Educação acabam se organizando de maneira a cumprir a carga horária mínima, sem se preocupar com a centralidade da proposição da formação continuada, que é de contribuir verdadeiramente ao cotidiano escolar.

Outro exemplo é a manipulação do Estado em relação ao estímulo da terceira via, onde a sociedade civil é estimulada diariamente a prestar trabalho voluntário a fim de substituir falta de professores e atividades, que deveriam ser oferecidas pelo setor público; o projeto Amigos da Escola tem sido um forte exemplo desta ação.

Nesta perspectiva, encontra-se a ampla divulgação que tem sido feita pelo SESC, que instituiu o programa EDUCASESC, destinado a promover encontros para formação continuada dos professores da rede pública. Nesses encontros, nos quais já tivemos a oportunidade de participar, observamos a desconexão em relação à realidade escolar, uma vez que as atividades têm sido planejadas e programadas por pessoas que nem sempre conhecem ou visitaram alguma escola; todavia oferecem palestras que julgam importantes, mas que, por vezes, apenas reproduzem a lógica do capitalismo.

Observa-se que ONU, CEPAL, UNESCO, FMI e BIRD, possuem uma linguagem universal, uma vez que todos justificam o modo de produção capitalista pelas mesmas metas. Nessa perspectiva, propõem uma educação voltada para a preparação do indivíduo que atenda ao mercado de trabalho, ou seja, uma educação que disponibilize força de trabalho qualificada para que possam competir no mercado nacional e internacional. A escola passa a ser um meio de transmissão direta e indireta dos princípios doutrinários da ideologia dominante, cabendo ao professor reproduzir tal ideologia, ou seja, para essas organizações.

Em âmbito Federal ${ }^{9}$ (Brasil) e Estadual ${ }^{10}$ (Paraná), a formação continuada tem sido incorporada no escopo de ações (projetos de governos e políticas públicas) inerentes à organização da educação em todos seus níveis, etapas e modalidades, ou seja, tem-se traduzido em atividades ligadas ao ato de ser professor, ainda que seja esporadicamente (início de semestres) e/ou frequente (quinzenalmente, mensalmente), presencial e/ou a distância, específica e/ou genérica. De alguma maneira, a formação continuada tem feito parte do cotidiano do professor.

Diante destas pontuações, evidencia-se a necessidade de, ao pensarmos em formação continuada, compreender a lógica, as implicações e as teorias nas quais se baseiam as propostas de formação, a fim de termos conhecimento sobre o universo que envolve esta ação, uma vez que toda e qualquer ação tem por trás diversos objetivos e intenções, tanto de quem organiza, quanto de quem participa e isto deve estar claro para quej possamos, por meio da formação continuada, alcançar nossas expectativas e metas enquanto profissionais da educação comprometidos com uma educação significativa, que esteja além de ideais político-partidários e/ou capitalistas, mas tendo como suporte uma política que aponte para uma formação crítica, participativa e transformadora do ser humano na busca de uma sociedade mais igualitária.

\section{Conclusão}

Programas eficientes de formação continuada, com base em políticas públicas claras, tanto em sua dimensão ampla quanto específica, são necessários e urgentes para que a formação inicial tenha possibilidade de se atualizar permanentemente respondendo aos novos desafios do ensino e da aprendizagem dos conteúdos científico-culturais.

Para uma efetiva formação continuada, são necessários novos programas, novos métodos, uso de novos recursos tecnológicos para articular os saberes científico-culturais indispensáveis para a aprendizagem dos alunos como cidadãos e futuros profissionais. Isso deve ser previsto tanto na dimensão teórica quanto na prática em todos os cursos e processos de formação continuada.

Os professores da atualidade têm o privilégio de poder ter acesso a todas as mudanças que ocorrem em torno do conhecimento científico, simplesmente consultando os diversos registros que existem e são de fácil acesso para podermos aprender e compreendê-los a fim de levá-los ao conhecimento dos alunos. Esta possibilidade, contudo, não

9 Lei nº 9.394 de 1996, que estabelece as Diretrizes e Bases da Educação Nacional (LDB), as Diretrizes Curriculares Nacionais para a Educação Básica (2013) e o Plano Nacional de Educação, aprovado pelo Congresso Nacional em 26 de junho de 2014. Constituição da República Federativa do Brasil (1988) e o Estatuto da Criança e do Adolescente (1990), além de diversas resoluções do Conselho Nacional da Educação que orientam a educação em todos seus níveis, etapas e modalidades no Brasil.

10 Lei n ${ }^{\circ} 18.492$ que estabelece o Plano Estadual de Educação do Paraná (2015-2015), Diretrizes Curriculares Estaduais publicadas a partir de 2008, por disciplinas, modalidades e temáticas, dentre as quais a de "Orientações curriculares para o curso de formação de docentes da educação infantil e anos iniciais do ensino fundamental, em nível médio, na modalidade normal”, publicada no ano de 2014; além diversas resoluções do Conselho Estadual de Educação que orientam a educação em todos seus níveis, etapas e modalidades no Paraná. 
dispensa a formação continuada formal, porque o processo didático-pedagógico não é uma ação individual, mas sempre um fazer coletivo no contexto escolar e social.

Assim, são necessárias formações continuadas para que os professores conheçam as reais dimensões políticas da educação brasileira e os novos processos teórico-práticotecnológicos de ensinar os conteúdos científico-culturais com significado e sentido para os alunos, possibilitando que se tonem conscientes de seus direitos e deveres como cidadãos e como futuros profissionais, atuando na perspectiva da transformação social pela aplicação social dos conhecimentos adquiridos na escola.

A formação continuada no mundo atual, enquanto necessidade de todos profissionais, não pode ser reduzida a uma ação compensatória de fragilidades da formação inicial, mas como um encaminhamento permanente para a melhoria da qualidade de ensino, tanto em sua dimensão teórica quanto prática.

Destarte, a formação continuada deve estar o mais próximo possível da realidade escolar, contribuindo como um dos agentes fundamentais para que os professores consigam compreender a si, ao outro, à sociedade vigente, enfim, compreender o homem como sujeito histórico que constrói e reconstrói conhecimento ao longo de toda sua vida. Deve ser considerada como um dos elos da corrente em prol da educação com qualidade.

Devemos avançar no sentido de superar a concepção de formação atrelada somente à capacitação, que acaba sendo organizada e realizada como momentos pontuais e fragmentados, que trazem algumas receitas paliativas, mas que são ineficientes diante das reais necessidades que o cotidiano escolar apresenta.

É preciso pensar a formação continuada com base teórica sólida, integrada ao cotidiano escolar, com princípios voltados para a qualidade e relevância. Para tanto, é necessário que o Estado assuma seu papel, assegurando, com recursos próprios, as estruturas necessárias para a viabilização desta formação, seja por meio de recursos financeiros e/ou recursos físicos, materiais e humanos.

Observa-se que, dentre os vários desafios da educação, a formação é algo que merece destaque, uma vez que, enquanto profissionais da educação, estes possuem condições e para contribuir sistematicamente no processo. A formação continuada é uma questão institucional sim, mas que precisa ser melhor sistematizada, debatida e articulada, seja nas instituições de Educação Básica, seja nas instituições de Ensino Superior.

Além disso, faz-se necessário ter clareza sobre os reais objetivos do financiamento proposto pelo Banco Mundial, que busca integrar os objetivos dos projetos educacionais à política de desenvolvimento do Banco e da comunidade internacional, além do caráter compensatório atribuído à educação, numa perspectiva de que por si só poderá aliviar a situação de pobreza dos países subdesenvolvidos.
São necessários cursos de formação continuada, para uma análise crítica dos objetivos neoliberais, pois muitas vezes a formação continuada alimenta a lógica do capitalismo, ou ainda, é vista como ação para dar conta das fragilidades da formação inicial, o que deve ser analisado de uma maneira mais ampla, pois embora existam graduações que deixam a desejar na preparação efetiva dos professores, existem mecanismo de apropriação do conhecimento que só se efetivam ao longo da vivência profissional.

Não é por falta de leis, programas e ou estudos científicos que a formação continuada dos professores vai mal. $\mathrm{O}$ que existe é um abismo entre o que está sendo garantido no papel, o que está se efetivando na prática e o que está repercutindo na atuação cotidiana deste profissional.

Uma formação continuada, pautada na visão dialética do sujeito, afastará o processo de ensino e aprendizagem da lógica do mercado, ou seja, embora saibamos que a formação escolar tem sido requisito para inserção no mercado de trabalho, a escola não pode ficar à mercê dos imperativos da economia.

É preciso que, estando alicerçados na história e diante das relações que se estabelecem na sociedade atual e, especificamente, no processo de ensino e aprendizagem tracemos nossas ações com coerência e percepção da influência das tendências políticas e sociais da sociedade capitalista na qual vivemos.

Desta forma, propomos que os professores conheçam as políticas públicas de educação e de formação continuada, mas ao mesmo tempo atualizem o conteúdo específico que ministram, em sua dimensão teórica e na dimensão de uso social. Essas dimensões podem ser unidas na medida em que os professores incorporam, dentro da formação inicial e continuada, os elementos teóricos e práticos que se transformarão em ferramentas necessárias ao processo de transposição didática do conhecimento, no cotidiano escolar. Isto significa que, ao longo de sua formação, tanto inicial quanto continuada, os professores precisam se apropriar de instrumentos que lhes permitam conhecer, ampliar e aprofundar os elementos inerentes às diferentes dimensões teóricas e práticas do conteúdo e de formas eficientes para que os educandos incorporem o conhecimento ensinado.

Apesar de vivermos em uma sociedade onde as relações se estabelecem a partir do dinheiro (trabalho com valor de troca e não valor de uso), e da escola ser mais um dos mecanismos institucionalizados que visam a manutenção desta organização social, acreditamos que é possível, por meio da educação, na perspectiva da emancipação humana e não somente da emancipação política, possibilitarmos vivências que valorizem as relações humanas, onde o acesso ao conhecimento, para além das relações capitalistas, garanta os elementos que viabilizam a compreensão e o respeito na construção e reconstrução do conhecimento, pelo simples fato de constituir-se como produto inerente à produção da existência humana. 


\section{Referências}

ANFOPE - Associação Nacional pela Formação dos Profissionais da Educação. In: Encontro Nacional da ANFOPE, 10., 2000, Brasília, DF. Documento Final. Brasília, DF, 2000.

BANCO MUNDIAL. Prioridades y estrategias para la educacion: examen del Banco Mundial. Washington: Biblioteca del Congreso de los Estados Unidos, 1996.

BORGES, M.D.A. O Brasil e os compromissos internacionais na área da Educação. In: CONFERÊNCIA NACIONAL DE EDUCAÇÃO, CULTURA E DESPORTO. Desafios para o século XXI: coletânea de textos 1. Brasília: Câmara dos Deputados, 2001. p.308-313.

BRASIL. Conselho Nacional de Educação. Conselho Pleno. RESOLUÇÃO CNE $/ C P n^{\circ} 1$, de 18 de fevereiro de 2002. Institui Diretrizes Curriculares Nacionais para a Formação de Professores da Educação Básica, em nível superior, curso de licenciatura, de graduação plena. Brasília, 2002.

BRASIL. Ministério da Educação. Documento Base da Conferência Nacional da Educação Básica. Brasília: MEC, 2008.

BRASIL. Ministério da Educação Lei de Diretrizes e Bases da Educação Nacional. Lei n. ${ }^{\circ}$ 9.394, de 20 de dezembro de 1996. Estabelece as diretrizes e bases da educação nacional. Diário Oficial da União, Brasília, DF, 23 dez. 1996.

BRASIL. Ministério da Educação. Conselho Nacional de Educação. Conselho Pleno. RESOLUÇÃO CNE/CP $n^{\circ} 2$, de $1^{\circ}$ de julho de 2015. Define as Diretrizes Curriculares Nacionais para a formação inicial em nível superior (cursos de licenciatura, cursos de formação pedagógica para graduados e cursos de segunda licenciatura) e para a formação continuada. Brasília, 2015.

BRASIL. Ministério da Educação. Plano Nacional de Educação. Lei ${ }^{\circ} 13.005$, de 25 de junho de 2014. Aprova o Plano Nacional de Educação e dá outras providências. Diário Oficial da União, Brasília, 2014.

BRASLAVSKY, B. O meio e o professor do ponto de vista de diversas perspectivas da alfabetização inicial. In: SERBINO, R.V. et al. (Org.). Formação de professores. São Paulo: Fundação Editora UNESP, 1998. p.59-84.

BRZEZINSKI, I. Notas sobre o currículo na formação de professores: teoria e prática. In: SERBINO, R.V. et al. (Org.). Formação de professores. São Paulo: UNESP, 1998.

CAGLIARI, L. C. Alfabetizando sem o Bá-bé-bi-bó-bú. São Paulo: Scipione, 2009.

CAMARGO, E.A.S.P. et al. Educação: de direito de cidadania a mercadoria. Educ. Soc., v.24, n.84, p.727-732, 2003.

CEPAL. UNESCO. Educação e Conhecimento: eixo da transformação produtiva com equidade. Brasília: IPEA/CEPAL/ INEP, 1995 .

CONTINUADA. In: Novo Dicionário Aurélio. Curitiba: Positivo, 2004.

DELORS, J. et al. Educação um Tesouro a Descobrir: relatório para a UNESCO da Comissão Internacional sobre Educação para o século XXI. São Paulo: Cortez, 1998.

DUARTE, N. A anatomia do homem é a chave da anatomia do macaco: a dialética em Vygotski e em Marx e a questão do saber objetivo na educação escolar. Educ. Soc., v.21, n.71, p.79-115, 2000 .

FONSECA, M. O financiamento do Banco Mundial à educação brasileira: vinte anos de cooperação internacional. In: TOMMASI, L.; WARDE, M.J; HADDAD, S. (Org.). O Banco Mundial e as Políticas Educacionais. São Paulo: Cortez. 2003.

FORMAÇÃO. In: Novo Dicionário Aurélio. Curitiba: Positivo, 2004.

FREIRE, P. Pedagogia do oprimido. Rio de Janeiro: Paz e Terra, 1987.

LIBÂNEO, J.C. Organização e gestão da escola: teoria e prática. São Paulo: Heccus, 2013.

MARRACH, S.A. Outras histórias da educação: do Iluminismo à Indústria Cultural (1823-2005). São Paulo: Unesp, 2009.

MAZZEU, F.J.C. Uma proposta metodológica para a formação continuada de professores nas perspectiva histórico-social. Cad. CEDES, v.19, n.44, p.59-72, 1998.

MELO, M. T. L. de. Programas oficiais para formação dos professores da Educação Básica. Educ. Soc., v.20, n.68, p.45-60, 1999.

OLIVEIRA, R. O legado da CEPAL à Educação nos anos 90. Rev. Iberoam. Educ.. p.1-14, 2003.

PEREIRA, C.E.C. Sociedade e educação. 2004. Disponível em: http://www.fclar.unesp.br/ced/polit gest/edi4 artigocarlos eduardo.pdf. Acesso em: 11 nov. 2019.

SAVIANI, D. Pedagogia Histórico-crítica: primeiras aproximações. Campinas: Autores Associados, 2011.

SILVA, M.A. O consenso de Washington e a privatização na educação brasileira. Linhas Críticas, v.11, n.21, p.255-264, 2005.

TARDIF, M. Saberes docentes e formação profissional. Petrópolis: Vozes, 2014.

ZANETTE, R. Relação Estado Educação no processo de Globalização neoliberal. 2018. Disponível em: http://www. centrorefeducacional.com.br/estaeduc.htm. Acesso em: 14 nov. 2019. 